Forum 2018 $33: 59$

https://doi.org/10.1007/s12312-017-0372-1

Online publiziert: 13. Dezember 2017

(c) Springer Medizin Verlag GmbH, ein Teil von

Springer Nature 2017

KREBSVERBAND

BADEN-WÜRTTEMBERG E.V.

Krebsverbandes Baden-Württemberg e.V.

Stuttgart, Deutschland

\title{
Anerkennungspreis für Matthias Villalobos
}

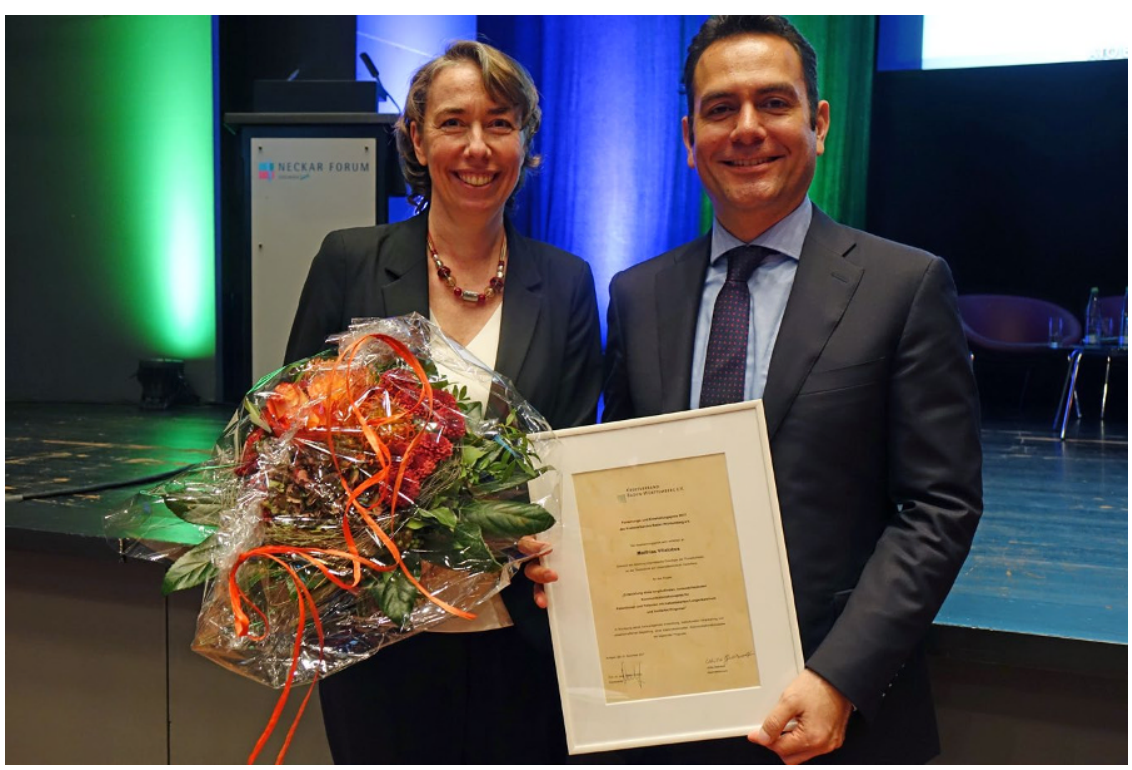

\ Anja Siegle und Dr. Matthias Villalobos, Thoraxklinik Heidelberg

an eine hohe Belastung durch körperliche Symptome, aber auch durch psychosoziale und existenzielle Sorgen haben, helfen.

Der Start zur Konzeptimplementierung ist nunmehr an der Thoraxklinik genommen: Gemeinsam mit Prof. Michel Wensing und seinem Team (Abteilung Allgemeinmedizin und Versorgungsforschung des Universitätsklinikums Heidelberg) sowie Frau Prof. Jana Jünger und ihrem Team (Direktorin des Instituts für medizinische und pharmazeutische Prüfungsfragen) wird die nächste Projektphase umgesetzt. Das Projekt wird vom Bundesgesundheitsministerium gefördert.

\section{Korrespondenzadresse}

Anja Siegle, RN, M. A.,

Thoraxklinik - Heidelberg gGmbH

Universitätsklinikum Heidelberg

Röntgenstr. 1

69126 Heidelberg

Tel.: 06221-396 8215

Anja.Siegle@med.uni-heidelberg.de

\section{Ulrika Gebhardt}

Krebsverband Baden-Württemberg e.V.

Adalbert-Stifter Straße 105

70437 Stuttgart

Tel: 0711 848-10770

info@krebsverband-bw.de

\section{Literatur}

1. Villalobos M (2017) Heidelberger MeilensteinKommunikation - HeiMeKOM. Forum 32:436. https://doi.org/10.1007/s12312-017-0335-6 